\title{
Nurses, information use, and clinical decision making - the real world potential for evidence-based decisions in nursing
}

$\mathrm{N}$ urses have probably always known that their decisions have important implications for patient outcomes. Increasingly, however, they are being cast in the role of active decision makers in healthcare by policy makers and other members of the healthcare team. In the UK, for example, the Chief Nursing Officer recently outlined 10 key tasks for nurses as part of the National Health Service's modernisation agenda and the breaking down of artificial boundaries between medicine and nursing. ${ }^{1}$ As well, nurses are expected to access, appraise, and incorporate research evidence into their professional judgment and clinical decision making. ${ }^{2}$ This active engagement with research evidence is the focus of this paper. We will explore why it is necessary to consider the clinical decision making context when examining the ways in which nurses engage with research based information. We will also consider the relation between the accessibility and usefulness of information from different sources and the decisions to which such information is applied. Finally, we will argue that if we are to encourage nurses to actively engage with research evidence during clinical decision making, we need to better understand the relation between the decisions that nurses make and the knowledge that informs them.

\section{METHODS UNDERPINNING THIS PAPER}

In this paper, we draw heavily on the findings of 2 major studies conducted at the University of York between 1997 and 2002..$^{3-9} 2$ case studies were conducted in 3 geographical areas with different hospital types, population characteristics, and levels of health service provision. We purposively sampled participants according to a sampling frame constructed around variables deemed to be theoretically significant for clinical decision making. ${ }^{7}$ Data collection comprised 200 indepth interviews with nurses and managers; 400 hours of nonparticipant observation of "decision making and information use in action"; 4000 practice based documents audited for characteristics such as age, research basis, authorship, etc; and statistically modelled (using the Q methodology approach) ${ }^{10}$ perspectives on the accessibility, usefulness, and barriers to use of information sources from 242 nurses.

\section{EVIDENCE-BASED DECISION MAKING INVOLVES ACTIVELY USING INFORMATION}

Evidence-based decision making involves combining the knowledge arising from one's clinical expertise, patient preferences, and research evidence within the context of available resources. ${ }^{11}$ Evidence-based decision making-like all decision making-involves choosing from a discrete range of options, which may include doing nothing or a "wait and see" strategy. All such choices are informed by an evaluation of available information: the process of using clinical judgment. In making evidence-based decisions, research evidence should not be taken at face value and adhered to uncritically, but should be given an appropriate weight in a decision depending on its internal and external validity. Integrating research evidence into decision making involves forming a focused clinical question in response to a recognised information need, searching for the most appropriate evidence to meet that need, critically appraising the retrieved evidence, incorporating the evidence into a strategy for action, and evaluating the effects of any decisions and actions taken. These steps are important components of the active process that is evidence-based decision making.

Evidence-based decision making is a prescriptive approach to making choices, which is based on ideas of how theory can be used to improve real world decision making. However, before we plan a strategy to attain this ideal, it is important to identify our starting point: how do nurses currently use (and view) research based information in decision making? Surprisingly, little research has been done on this topic, except for studies that use self report data from nurses as a source of evidence. We reject self report as the main source of evidence for answering our questions in favour of "real time" clinical observation and indepth interviews, which we feel better reflect actual types and frequencies of different decisions and observed information use.

\section{INFORMATION NEED, "INFORMATION BEHAVIOUR,"' AND CLINICAL DECISION MAKING} One of the challenges of researching how people respond to information deficits is that such deficits, or information needs, are unobservable. "Information need" is a construct that exists only in the mind of the person "in need."12 Researchers can only hypothesise about the likely needs of nurses based on what they say, what we can deduce from watching their behaviour, or preferably both. "Need" cannot be separated from the motives of information seeking behaviour. If an information need is to be converted into action (eg, reading Evidence-Based Nursing or accessing the Cochrane Library), then individuals must have a motive for doing so. In developing motives, individuals draw on personal frameworks of beliefs and values, which contain objects that have satisfied information needs in the past. Some objects (eg, MEDLINE) may be valued less than others (eg, knowledgeable colleagues) because they previously failed to satisfy information needs. ${ }^{12}$

For proponents of evidence-based decision making, the primary motive for engaging with research based information is to reduce clinical uncertainty; that is, finding relevant research will increase one's certainty that a particular course of action is most likely to lead to the desired outcomes. ${ }^{13}$ However, new information can also elucidate and/or confirm existing information, beliefs, and values. Nurses often report that their rationale for seeking research evidence is to support their existing practice. The processes of searching for, appraising, and integrating research information with existing knowledge have been labelled "information behaviour" by some researchers in the field of information science. ${ }^{14}$

The types of clinical decisions that nurses actually make provide clues about how (and what types of) research information might assist in decision making. Other authors have examined the clinical decisions of healthcare professionals (and the clinical questions arising from such decisions) as 
expressions of potential information need. ${ }^{15}$ Thus, decisions are an important context for information use. We will show how understanding the structure and characteristics of the decisions nurses face is important for understanding the ways in which information is accessed and processed by nurses.

\section{NURSES' CLINICAL DECISIONS: A TYPOLOGY}

The table provides a typology of clinical decisions, with examples that were derived from interviews with, and observation of, acute and primary care nurses.. ${ }^{3-9}$ These decisions represent core choices that are only part of the architecture of the decision making context for applying research knowledge. Nurses described several other elements of their clinical decisions and decision making processes.

\section{Frequency of decision making}

The number and types of decisions faced by nurses are related to the work environment, perceptions of their clinical role, operational autonomy, and the degree to which they see themselves as active and influential decision makers. Nurses working on a busy medical admissions unit admitting 50 patients per day face a different set of decision challenges compared with health visitors (HVs) or public health nurses, who may see 10 patients per day. Consider the extent to which judgment and choices feature in this HV's consultation:

"She was breast-feeding but had very sore cracked and bleeding nipples on her left breast and she did not know what to do about it. [What did the HV think? The mother asked] The HV thought and replied that she had not come across this problem before, but asked if it was painful. Mum said that it was and she had tried to feed her from this breast but it was so painful that she had not done so. She had only fed from the right breast and for the past three evenings the baby had fed continuously for six hours and then slept all night. Someone had suggested using Camillosan cream for her cracked nipples but it had not helped at all. However she knew that chamomile was a relaxant and maybe that was why the baby had slept for so long the last three nights. The HV mentioned a nipple shield but said that she had no experience of using them. The mum said that she wondered if she should just stop feeding from that breast altogether until they had healed, to which the HV agreed. The HV then said that if she was having pain in her breast, that could indicate that she had a thrush infection on her breast. She then asked if she had seen any white patches on the baby's tongue or in her mouth and mum replied that she had not. No more was said about that. They agreed that mum would not feed from her left breast and only use her right until it healed up. The HV said that as the baby was feeding well from her right breast then that was OK." (Field notes, health visitor).

This quote illustrates at least 5 judgment or decision challenges for the $\mathrm{HV}$, all of which generate potential information needs: (1) ascertain the likely causes of sore and cracked nipples; (2) choose a management strategy in the context of little or no experiential knowledge; (3) judge whether the baby is getting sufficient breast milk; (4) choose between the merits of Camillosan, Chamomile, or a nipple shield; and (5) identify the cause of pain (possibly thrush).

\section{Decisional complexity}

Three elements of decisional complexity that permeated nurses' accounts of their decisions are described below.

Time limited decision making activity. Nurses described situations in which rapid decisions were expected (a phenomenon known as implied response time). ${ }^{16}$ Consequently,

Decision types and clinical questions/choices expressed by acute and primary care nurses

\begin{tabular}{|c|c|}
\hline Decision type & Example of clinical questions/choices \\
\hline $\begin{array}{l}\text { Intervention/effectiveness: decisions that involve choosing among } \\
\text { interventions. } \\
\text { Targeting: a subcategory of intervention/effectiveness decisions } \\
\text { outlined above, of the form "choosing which patient will benefit most } \\
\text { from the intervention." }\end{array}$ & $\begin{array}{l}\text { Choosing a mattress for a frail elderly man who has been admitted with an acute } \\
\text { bowel obstruction. } \\
\text { Deciding which patients should get antiembolic stockings. }\end{array}$ \\
\hline $\begin{array}{l}\text { Prevention: deciding which intervention is most likely to prevent } \\
\text { occurrence of a particular health state or outcome. } \\
\text { Timing: choosing the best time to deploy the intervention. }\end{array}$ & $\begin{array}{l}\text { Choosing which management strategy is most likely to prevent recurrence of a } \\
\text { healed leg ulcer. } \\
\text { Choosing a time to begin asthma education for newly diagnosed patients with } \\
\text { asthma. }\end{array}$ \\
\hline $\begin{array}{l}\text { Referral: choosing to whom a patient's diagnosis or management } \\
\text { should be referred. }\end{array}$ & $\begin{array}{l}\text { Choosing that a patient's leg ulcer is arterial rather than venous and merits medical } \\
\text { rather than nursing management in the community. }\end{array}$ \\
\hline $\begin{array}{l}\text { Communication: choosing ways of delivering information to and receiving } \\
\text { information from patients, families, or colleagues. Sometimes these } \\
\text { decisions are specifically related to the communication of risks and } \\
\text { benefits of different interventions or prognostic categories. }\end{array}$ & $\begin{array}{l}\text { Choosing how to approach cardiac rehabilitation with an elderly patient who has } \\
\text { had an acute myocardial infarction and lives alone, with her family nearby. }\end{array}$ \\
\hline $\begin{array}{l}\text { Service organisation, delivery, and management: these types of decisions } \\
\text { concern the configuration or processes of service delivery. }\end{array}$ & Choosing how to organise handover so that communication is most effective. \\
\hline $\begin{array}{l}\text { Assessment: deciding that an assessment is required and/or what mode } \\
\text { of assessment to use. }\end{array}$ & Deciding to use the Edinburgh Postnatal Depression screening tool. \\
\hline $\begin{array}{l}\text { Diagnosis: classifying signs and symptoms as a basis for a management } \\
\text { or treatment strategy. }\end{array}$ & $\begin{array}{l}\text { Deciding whether thrush or another cause is the reason for a woman's sore and } \\
\text { cracked nipples. }\end{array}$ \\
\hline $\begin{array}{l}\text { Information seeking: the choice to seek (or not to seek) further information } \\
\text { before making a further clinical decision. }\end{array}$ & $\begin{array}{l}\text { Deciding that a guideline for monitoring patients who have had their ACE inhibitor } \\
\text { dosage adjusted may be of use, but choosing not to use it before asking a } \\
\text { colleague. }\end{array}$ \\
\hline $\begin{array}{l}\text { Experiential, understanding, or hermeneutic: relates to the interpretation } \\
\text { of cues in the process of care. }\end{array}$ & $\begin{array}{l}\text { Choosing how to reassure a patient who is worried about cardiac arrest after } \\
\text { witnessing another patient arresting. }\end{array}$ \\
\hline
\end{tabular}


70

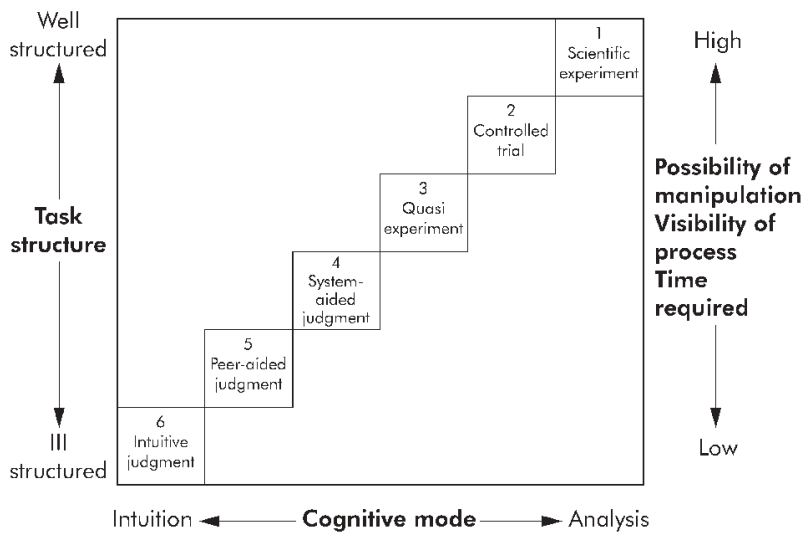

The cognitive continuum.

Reproduced with permission from Hamm RM. Clinical intuition and clinical analysis: expertise and the cognitive continuum. In Dowie J, Elstein A, editors. Professional judgement: a reader in clinical decision making. Cambridge: Cambridge University Press, 1988:87.

opportunities for seeking information beyond what was readily available were perceived as severely restricted. Limited time was a primary reason for the "separation" of day to day decision making from information seeking and appraisal. Despite these constraints on information use, some nurses felt that as their expertise developed, they managed to reduce contact time with patients by virtue of having to spend less time seeking information to reduce uncertainty in decision making. Decision related information seeking was associated with novice rather than expert performance.

Multiple and diverse decision goals. The stepwise nature of information gathering and decision making in patient encounters, as well as the need to foster patient perceptions of trust and credibility in the nurse, meant that decisions often had multiple and conflicting decision goals. For example, one HV described the need to build confidence in a young mother, leading her to sanction weaning at 12 weeks rather than (for her) the more optimal 16 weeks (current best evidence suggests that the optimum time for weaning is 24 weeks). ${ }^{17}$

Conflicting decision elements. As well as making decisions more complex, conflict can also simplify decisions. The following example of conflict in nurse-doctor power relations demonstrates this point:

"When S came back she cleaned the patient's left leg with gauze soaked in saline and then applied a dressing (Jelonet). She said that she felt Jelonet was not ideal but the patient's consultant preferred it despite the fact that 'when you take it off you are removing the good tissue as well.' Even if I change the dressing, when the patient goes to the outpatients' department and sees the consultant they will come back with Jelonet and clear instructions that we are to use Jelonet." (Field notes, district nurse)

\section{THE COGNITIVE CONTINUUM: THE DECISION AS DRIVER FOR INFORMATION BEHAVIOUR}

Since the 1960s, cognitive psychologists and decision theorists have developed the idea of the cognitive continuum. ${ }^{16}{ }^{18}$ This model suggests that the major determinants of whether a person engages in intuitive decision making (ie, less likely to engage in evidence-based decision making) or rational decision making (ie, more likely to engage in evidence-based decision making) depends on where a decision "task," such as selecting a nursing intervention, lies on a (cognitive) continuum (figure). This cognitive continuum has 3 dimensions, ${ }^{16}{ }^{19}$ which are described below.

Complexity of the task: the number of information cues (the more cues required for a decision, the more likely it is that nurses will fall back on intuitive reasoning); the number of judgment "steps" required to make a choice (eg, selecting interventions for patients with chronic and comorbid conditions and a lack of complete information readily available)

Ambiguity of the task: the task characteristics that induce rational information processing include the presence of easily available (cognitively) organising principles for collecting and handling information and simplifying decisions (known as feedforward) ${ }^{20}$; a familiar decision task with familiar content; the presence of an observable outcome for the task; and a degree of feedback on the likely success of the task. An example of a task that is more likely to induce rational processing (and draw on knowledge derived from research) is the assessment and treatment of chronic venous leg ulcers. Nurses assessing and treating leg ulcers identified the helpful role of the UK Royal College of Nursing Guidelines ${ }^{21}$ in collecting the information required for a good assessment and decision, and the design of training, audit, and feedback around the guidelines and decision making in leg ulcer care.

Form of task presentation: very short time frames for exercising judgment are more likely to induce intuitive information handling. Alternatively, breaking the task down into components (decomposition) induces rationality in handling clinical information, as do information cues that are dichotomous or discrete (eg, "this Doppler reading indicates either venous or arterial aetiology"); similarly, the greater the need to make a decision "visible" to others, the greater the use of analytic reasoning.

The relative balance in the mixture of intuition- and rationality-inducing task elements predicts the end of the continuum to which cognition is drawn. Correctly "matching" information and the ways that it is processed (ie, using more systematic, rational methods rather than intuition) to the nature of decision tasks results in better decision performance. $^{18}$

Knowledge of a decision task alone, however, is not a sufficient basis for predicting whether a person will use analytic or intuitive reasoning, or indeed, whether they will even gather the information necessary to engage in analytic reasoning. Consider, for example, a primary care nurse who ignores the physical presence of a guideline during a consultation in favour of the more easily accessed (cognitively) knowledge of one's own memory and the advice of a colleague.

\section{THE REALITY OF INFORMATION BEHAVIOUR}

2 broad patterns of engagement among nurses, research based information, and clinical decision and judgment tasks were present in the studies.

\section{Preference for humans as information sources}

Both primary and acute care nurses were characterised by reliance on human sources of information as the primary means of informing situations in which they were uncertain. ${ }^{5}$ We identified 7 distinct perspectives on accessibility, all of which stress the relative accessibility of experiential sources of information, such as clinical nurse specialists (CNSs), experienced colleagues, and other primary and secondary care team colleagues. Notable exceptions were local protocols and guidelines in acute care (particularly in areas such as 
coronary care) and sources of drug related information, such as the British National Formulary, drug information sheets, and pharmacists in primary care. Even when textual information was seen as accessible, human sources of information were highly rated in terms of their accessibility. We also found that simple demographic or biographical variables, such as clinical experience, educational attainment, or role on the primary care team, were weak predictors of perspectives of accessible information sources.

The scale of the relative lack of engagement with information sources can be gleaned from our observational data. During 90 hours of observing district nurses in practice, we found that use of an information source while actually making a decision in the presence of a patient occurred only once, in the form of a telephone call to another clinician. Similarly, in acute care, 180 hours of observation (circa 1080 decisions) revealed only 2 forms of text based information used "in action:" local protocols or guidelines (used 4 times) and the British National Formulary (used 50 times).

It would be wrong to infer, however, that research based knowledge has no part in nurses' decision making. Rather, nurses chose not to use the systematic search-appraiseimplement cycle of evidence-based decision making in realtime for real clinical decisions with rapid implied response times. Nurses accessed "evidence-based" information sources-if they accessed them at all-in contexts other than immediate decision making environments. Nurses described contact with research based information sources in the context of continuing professional development and formal education or training. Other influences included being involved in the production of local protocols and guidelines and having to make sense of research such as clinical trials, or using research evidence to help resolve conflict between colleagues. Perceptions about the relative accessibility of human sources of information were mirrored when we asked nurses about the usefulness of different sources of information for clinical decision making.

\section{Useful information sources are grounded in clinical reality}

As with accessibility, we identified several important perspectives on the relative usefulness of different sources of information for clinical decision making. Each of these perspectives stressed the usefulness of sources that were based on experience rather than research. Colleagues, other members of the primary care team, or senior members of the clinical team were viewed as the most useful (and accessible) information sources. In acute care, the most useful source of information across all perspectives was the CNS, who seemed to embody the characteristics of useful information sources: directly answered the question posed; seen to be authoritative and trustworthy; provided (or could potentially provide) a balance of "background"13 (factual) knowledge as well as foreground (management) knowledge; provided supportive and unchallenging information; and had no or minimal associated need for critical appraisal.

Given these characteristics, it is easy to understand the appeal of CNSs (or other experience rich sources) as a source of information. A district nurse described a link nurse colleague (a nurse who is responsible for a particular area of knowledge and practice, such as diabetes or wound care, and is often linked to the work of a CNS):

\footnotetext{
"They're (link nurses) specialists in the area that they cover, what's the point of reinventing the wheel? Me going to the library getting all the information and thinking, 'oh
}

I've done a good job there.' I can go to them and they've already got it... But it also gives you back up in areas where, I'm not a specialist... It's not just a short cut, it's that they're knowledgeable. They have the information there." (District nurse)

As with perceptions of accessibility, we found that demographic and biographic variables, such as age, clinical experience, and levels of educational attainment, were poor predictors of how useful an information source would be to a nurse.

\section{DECISION MAKING AND MODELS FOR THE IMPLEMENTATION OF RESEARCH KNOWLEDGE}

Many theoretical models of research utilisation implicitly recognise the importance of decision making as a vital step in the process of converting knowledge into action. Despite this implicit recognition, most models fail to account for the relation between decision characteristics, information use, and information processing. For example, Lomas ${ }^{22} 23$ has proposed a coordinated model of research implementation, which proposes that one end point of knowledge diffusion is negotiating the application of research findings with patients during the course of clinical practice. In other works, Lomas also calls for researchers and decision makers to have increased levels of understanding of each other's worlds if research and policy (or practice) are to be better linked. ${ }^{23}$ We would argue that although clinicians are making efforts to understand research (through initiatives such as critical appraisal training or, indeed, by reading journals such as Evidence-Based Nursing), researchers and disseminators often fail to fully understand the decisions to which their products are being applied. In relation to organisational policy decisions, Lomas suggests that researchers should endeavour to understand the institutional structures for decision making, the values (expressed as ideologies, beliefs, and interests), and the fact that there are often multiple producers of "evidence" (ie, information that actually gets used for decision making) existing within organisations. ${ }^{23}$ Other theorists who have attempted to build "context" into models of research utilisation also neglect the "micro" context of the actual decisions: their type, the time available, their perceived complexity, the amount of supporting (or challenging) information available, and the presence (or absence) of organising principles for this information. ${ }^{24}$

Some researchers have used clinical questions generated by clinical decisions as expressions of (potential) information need. ${ }^{6}{ }^{15}{ }^{25}$ We would argue that researchers need to delve deeper and begin to develop research exploring the relation between the information needs such questions represent and information behaviour by nurses. Moreover, we need to recognise that simply mapping the core choice at the heart of a decision (such as whether it arises from uncertainty about a diagnosis, treatment, or prognosis) is a necessary but insufficient condition for determining whether information is deemed relevant or rejected as irrelevant.

Thus far, we have focused on the links between information behaviour and clinical decision making from a researcher's perspective. It is important to recognise that the strategies available to clinical decision makers can also alter their relation with information. Using the principles of the cognitive continuum, it is possible to simplify decisions by removing some of their complexity in an effort to induce individuals to apply "search and appraisal" behaviour. For example, several nurses recounted the usefulness of a structured approach to gathering information as a means of simply gathering the "important" facts when faced with the 
72

complex judgment task of assessing a patient's chronic leg ulcer for venous or arterial aetiology. This structured bundle of facts (eg, Doppler reading, size, and history) formed the basis of management decisions that that were sometimes informed by appropriate national evidence-based guidelines (albeit often internalised). Similarly, the single area of decision making in which observable text based information use was (relatively) common was uncertainty about medication use. Nurses' accounts clearly showed that the sources of information used "fit" the questions that arose from their decisions-decisions that were often focused and well structured (eg, should I give this patient drug X or drug Y to achieve outcome $\mathrm{Z}$ ?).

This simplification induces shifts towards the rational end of the continuum. From this perspective, it is easy to imagine how thinking about the decisions nurses face in clinical practice might have an impact on their information behaviour. Indeed, some basic elements of the evidencebased nursing process could serve to simplify decisions. Specifically, the development of focused clinical questions can be conceptualised as a mechanism for removing some of the "noise" that surrounds choices and help focus attention on the relevant populations, outcomes, interventions, and the core type of uncertainty (diagnostic, intervention, or prognostic). Croskery proposes other, slightly more sophisticated, techniques under the banner of "cognitive forcing." ${ }^{26}$ These techniques involve retraining clinicians to think differently about problems by accounting for the effects of limited memory, erroneous perspectives (eg, ignoring base rates of disease when making diagnoses), limited capacity for self critique, and poor selection of strategies. The end result is a heightened sense of meta-cognition or "thinking about thinking." Research examining the potential of these types of approaches to reflection on action is missing in nursing.

\section{CONCLUSION}

Nurses are increasingly regarded as key decision makers within the healthcare team. They are also expected to use the best available evidence in their judgments and decisions. The prescriptive model of evidence-based decision making-and the search-appraise-implement process that accompanies itis an active process. Clinicians who want to implement research in clinical settings sometimes forget that active information seeking is only one of several possible responses to the irreducible uncertainties of clinical practice. In fact, observation of nurses in practice suggests that when "search and appraise" information behaviour occurs at all, nurses are far more likely to view colleagues ("human" sources of information) as useful and accessible sources of information than research in any form. Colleagues are perceived as delivering context specific, clinically relevant information that takes into account the needs of the judgment or decision situation and requires minimal critical appraisal; and they are time efficient. We would argue that this implies a degree of "fit" between the decision task and the information provided, although not necessarily the provision of high quality (ie, reliable or valid) information. Moreover, long standing theoretical frameworks explain this lack of fit between traditional evidence-based sources of research information and the decisions that nurses' face.

The cognitive continuum model offers a theoretical basis for a research agenda that is just emerging in nursing. Outlining the types of clinical decisions is only a starting point for this agenda. Future work should attempt to explore and explain the patterns of information use in decisions for which far more detailed maps exist. Moreover, there is a need for high quality development and evaluation of interventions that target evidence-based information provision at those individuals most likely to influence professional choices (eg, CNSs). We feel that such knowledge will add a valuable, and hitherto missing, dimension to existing models of research utilisation and knowledge transfer.

CARL THOMPSON, RN, PhD NICKY CULLUM, RN, PhD DOROTHY MCCAUGHAN, RN, MSC TREVOR SHELDON, DSC, FMedSci PAULINE RAYNOR, RN, HV(cert), PhD University of York York, UK

1 Chief Nursing Officer. PL CNO (2002) 5: Implementing the NHS Plan-Ten key roles for nurses. London: Department of Health, 2002. http:// www.dh.gov.uk/assetRoot/04/01/35/37/04013537.pdf.

2 Department of Health. Making a difference: strengthening the nursing, midwifery and health visiting contribution to health and healthcare. London: HMSO, 1999. http://www.dh.gov.uk/assetRoot/04/07/47/04/ 04074704.pdf.

3 McCaughan D. What decisions do nurses make? In Thompson C, Dowding D, editors. Clinical decision making and judgement in nursing. Edinburgh: Churchill Livingstone, 2001:95-108.

4 McCaughan D, Thompson C, Cullum N, et al. J Adv Nurs 2002;39:46-60.

5 Thompson C, McCaughan D, Cullum N, et al. J Adv Nurs 2001;36:11-22.

6 Thompson C, McCaughan D, Cullum N, et al. J Adv Nurs 2001;36:376-88.

7 Thompson C. Qual Health Res 1999;9:815-28.

8 Thompson C. J Adv Nurs 2003;43:230-7.

9 Thompson C, McCaughan D, Cullum N, et al. Int J Nurs Stud 2004;41:15-20.

10 Brown SR. Operant Subjectivity 1993;16:91-138.

11 DiCenso A, Cullum N, Ciliska D. Evidence-Based Nursing 1998;1:38-40.

12 Wilson T, Walsh C. Information behaviour: an inter-disciplinary perspective, British Library Research and Innovation Report 10. London: British Library Research and Innovation Centre, 1996. http://informationr.net/tdw/publ/ infbehav/prelims.html.

13 Sackett DL, Straus SE, Richardson WS, et al. Evidence based medicine: how to practice and teach EB. Second edition. London: Churchill Livingstone, 2000.

14 Case DO. Looking for information: a survey of research on information seeking, needs, and behaviour. London: Academic Press, 2002.

15 Cogdill KW. J Med Libr Assoc 2003;91:203-15.

$16 \mathrm{Hamm}$ RM. Clinical intuition and clinical analysis: expertise and the cognitive continuum. In Dowie J, Elstein A, editors. Professional judgement: a reader in clinical decision making. Cambridge: Cambridge University Press, 1988:78-105.

17 Pan American Health Organization and World Health Organization. Guiding principles for complementary feeding of the breastfed child. Washington: PAHO/WHO, 2001. http://www.paho.org/English/AD/FCH/NU/ Guiding_Principles_CF.htm.

18 Hammond KR, Hamm RM, Grassia J, et al. IEEE Transactions on Systems, Man, and Cybernetics 1987; 17:753-70.

19 Thompson C. J Adv Nurs 1999;30:1222-9.

20 Cooksey RW. Judgment analysis: theory, methods, and applications. New York: Academic Press, 1996

21 Duff L, Loffus-Hill A, Morrell C. Clinical guidelines for the management of venous leg ulcers. London: Royal College of Nursing, 2000:1-48.

22 Lomas J, Haynes RB. Am J Prev Med 1988;4(4suppl):77-94.

23 Lomas J. ISUMA 2000;1:140-44. http://www.isuma.net/v01n01/lomas/ lomas_e.pdf.

24 Rycroff-Malone J, Kitson A, Harvey G, et al. Qual Saf Health Care 2002;11:174-80.

25 Ely JW, Osheroff JA, Ebell MH, et al. BMJ 2002;324:710.

26 Croskerry P. Ann Emerg Med 2003;41:1 10-20. 